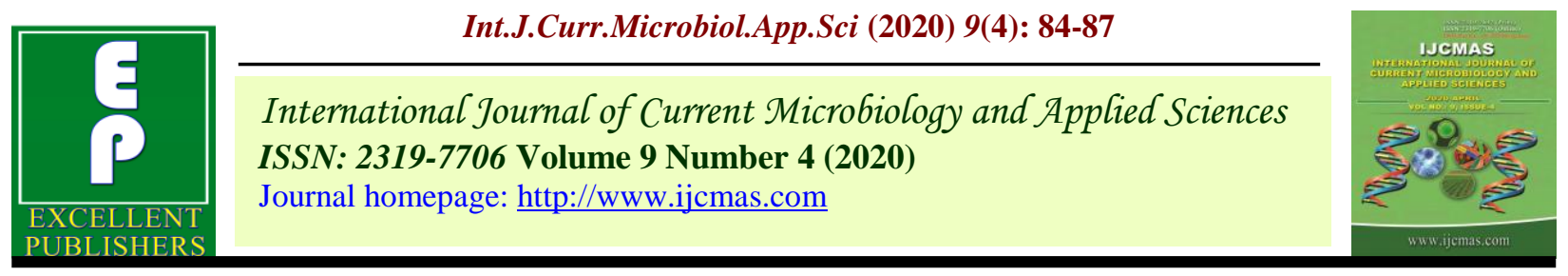

Case Study

https://doi.org/10.20546/ijcmas.2020.904.011

\title{
Chylothorax in a Dog - Diagnosis and Management
}

\author{
R. B. Vishnurahav*, Jiddu Joseph, Agas Mathew and S. Ajithkumar \\ University Veterinary Hospital and Teaching Veterinary and Clinical Complex \\ College of Veterinary and Animal Sciences University, Mannuthy, Thrissur -680651 \\ Kerala Veterinary and Animal Sciences University, Pookod, Wayanad, India \\ *Corresponding author
}

Keywords

Chylothorax,

Relaxzyme,

Thoracocentesis,

Solitary Ventricular

Premature

Complexes

Article Info

Accepted:

04 March 2020

Available Online:

10 April 2020

\section{A B S T R A C T}

Accumulation of chyle in the thoracic cavity is called as chylothorax. A five year old male Rottweiler was presented to the Teaching Veterinary Clinical Complex, Maanuthy with the history of limb edema and labored breathing. On auscultation of lung crackles and high intensity sounds and muffled heart sounds were observed. Radiography confirms the presence of effusion in the thoracic cavity. Solitary Ventricular Premature Complexes were observed in the three-minute electrocardiographic examination. Thoracic ultrasonography revealed anechoic areas, which confirmed pleural effusions. Thoracocentesis was done about two times and around $350 \mathrm{ml}$ of milky white fluid was collected each time for about 2 weeks interval between collections. It was clinically managed initially antibiotics and diuretics and some fluids. Later it was treated with Relaxzyme tablet followed by rutin. Dog was clinically improved. There was much reduction in fluid content, limb edema and respiratory distress.

\section{Introduction}

Chylothorax can be defined as the accumulation of chyle in the thoracic cavity. The predisposing factors were improper drainage of the thoracic duct or other conditions like trauma, obstructions and tumor masses. The most common clinical signs for chylothorax includes dyspnea, coughing, weight loss and anorexia and idiopathic in most of the animals. Other reported factors were dirofilariasis, neoplasia, cranial venavacal thrombosis, fungal granulomas and congenital abnormalities of thoracic duct (Fossum et al., 1986). Chyle is irritant and it may lead to inflammation and fibrosis of the thoracic wall lining, pleural surfaces and pericardial sac following its accumulation. When the conservative clinical management if not sufficient surgical operations can be done such as thoracic duct ligation, pleurodesis, pleuro venous shunting 
pleuro peritoneal shunting ,thoracic omentalization and pericardiectomy stated by (Birchard et al.,1982).

\section{Case history and observations}

A five year old male Rottweiler dog weighing $37 \mathrm{~kg}$ was brought to the University Veterinary Hospital and Teaching Veterinary Clinical Complex, College of Veterinary and Animal Sciences, Mannuthy with the history of limb edema labored breathing and anorexia. On physical examination, rectal temperature was found to be $102.4^{0} \mathrm{~F}$ with congested mucous membranes. Auscultation of lung revealed crackles and exaggerated sounds. Muffled heart sounds were observed. Radiography revealed increased soft tissue opacity, which suggests pleural effusions in the thoracic cavity (Fig. 3). Electrocardiogram showed ventricular premature contractions were observed. On echocardiography anechoic areas observed in the thoracic cavity indicative of pleural effusions. Hyperechoic movable thread like structures found in thoracic cavity were fibrin deposits (Fig. 2). Wet film, blood smear and buffy coat smear examination were found to be negative for moving blood parasites and other parasites. The blood picture was with mild anemia. Effusion collected from thoracic cavity was sent for estimation of triglycerides and cholesterol, total protein, albumin, cytology studies, culture and sensitivity examination. Incubation of pleural fluid had no growth for bacteria. Protein estimation of pleural fluid showed a slight increase in the value (observed-4.60g /dL, reference range: $<3$ for transudates, $>3$ for exudates). Triglycerides and cholesterol levels were measured in both thoracic effusion and serum. Higher levels of triglycerides were observed in effusion $(1154 \mathrm{mg} / \mathrm{dL})$ than in serum $(234 \mathrm{mg} / \mathrm{dL})$. (Fig. 1 showing animal presented to TVCC Mannuthy).

\section{Treatment and Discussion}

Ultrasound guided thoracocentesis was carried out as per standard protocol at the level of 7 to $9^{\text {th }}$ intercostal space with the analgesic butorphanol and local anesthetic lignocaine. Around $750 \mathrm{ml}$ of milky whitish fluid was removed at different intervals to relieve the respiratory distress to the animal (Fig. 4). Aspirated fluid was subjected to ether clearance test and result was more suggestive of chylous effusion. Furosemide @ $2 \mathrm{mg} / \mathrm{kg}$ BW PO BID, enrofloxacin $5 \mathrm{mg} / \mathrm{kg}$ BW PO OD and tablet relaxzyme 1 tab PO BID was started initially for a week. After a week animal showed slight improvement in condition and subsequent review tablet relaxyzyme was replaced by Rutin tablet 50 $\mathrm{mg} / \mathrm{kg}$ PO BID for a month with less fat diets and minimal physical activities. Radiography of thorax revealed reduced plueral effusions after a month. On further examination animal improved in condition no respiratory distress could be observed thereafter and a tremendous reduction in plueral effusions and limb oedema.

Chylothorax, characterized by the accumulation of chyle with in the thoracic cavity, is a relatively uncommon that affects dogs. Hayash et al., (2005) reported that the cisterna chyli ablation with thoracic duct ligation (TDL) may improve the outcome of chylothorax in dogs. Successful treatment using omentalization, which involves bringing a flap of omentum through the diaphragm and anchoring it to the mediastinus between the thoracic duct and the cranial venacava, has been reported in one dog (William and niles, 1999).

Non surgical treatment of chylothorax can include plueral evacuation, dietry modification and various drug therapies. Initial therapy for dogs diagnosed with chylothorax involves plueral evacuation with 
intermittent thoracocentesis. Plueral evacuation is performed to temporarly alleviate respiratory compromise, improves patients comfort and to obtain samples for diagnostic evaluation. Thisplueral effusion

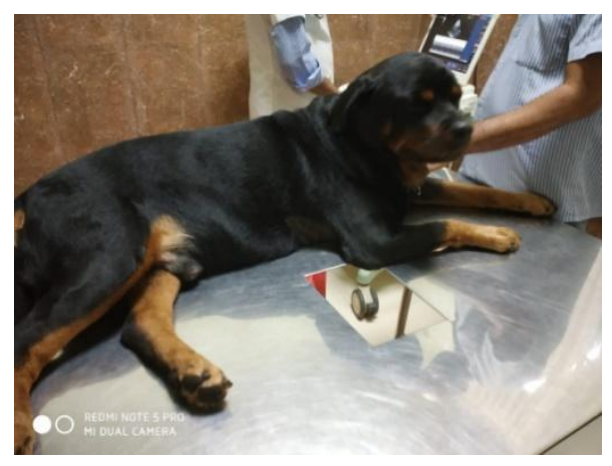

Fig.1

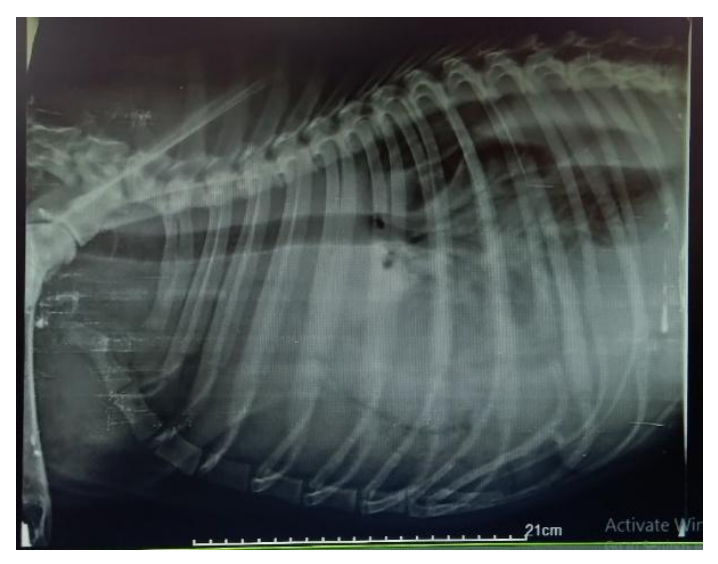

Fig.3 Thoracic Radiography (Right lateral) (Pleural effussion)

Pharmaceutical treatment using frusemide and corticosteroids had shown some results. Rutin, a benzopyrone derived from the Brazilian fava $d$ anta tree, is commonly used adjunctively in the non surgical management of idiopathic chylothorax condition. It has not shown any adverse effect in veterinary patients. The exact mechanism of action of rutin is still unknown however, increasing the uptake of edema fluid by lymphatic vessels, reducing the blood vessel permeability and alone cannot deal with the condition because it is not dealing with the underlying causes, therefore it is unlikely to resolve the condition.

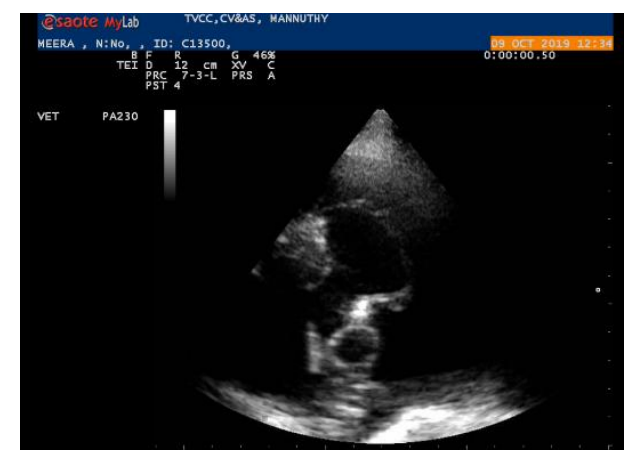

Fig.2 Thoracic Ultrasonography (Pleural effusion, fibrin deposits)

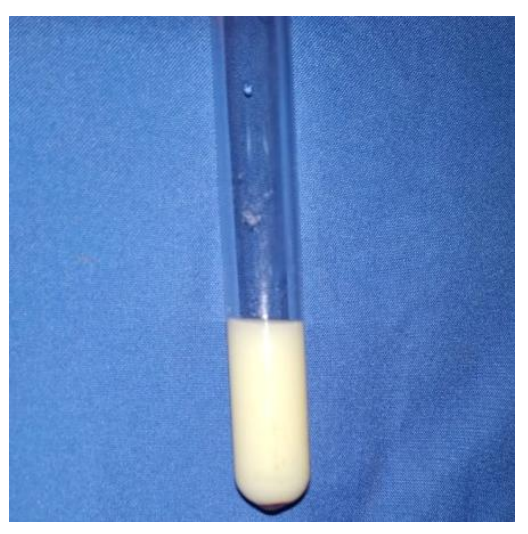

Fig.4 Chyle (Milky white fluid)

increasing tissue macrophage activity and thereby promoting phagocytosis of protein in edema fluid are suggested ones. Here in this case rutin helped to relieve idiopathic chylothorax condition to a greater extent. Ameetsingh et al., (2012) states that idiopathic chylothorax treated by non surgical methods like plueral evacuation and treatment with Rutin showed about 26\% \& $40 \%$ success rate respectively. 


\section{References}

Ameetsingh, Brigitte Brisson, Stephaine Nykamp. 2012. Idiopathic Chylothorax in Dogs and Cats: Non surgical and Surgical Management (compendium: continuing education for veterinarians)

Bichard, S.J., Cntwell, H.D and Bright R.M. 1982. Lymphangiography and ligation of the canine thoracic duct, a study in normal dogs and three dogs with
Chylothorax. J. Anim. Hosp. Assoc. 18: 769-777.

Fossum, T.W., Birchard, S.J and Jacobs R.M. 1986. Chylothorax in thirty-four dogs: A retrospective study. J. Am. Vet. Med. Assoc. 188: 1315-1317

Williams, J.M and Niles, J.D. 1999. Use of omentum as a physiological drain for the treatment of chylothorax in a dog. Vet. Surg. 28: 61-65.

\section{How to cite this article:}

Vishnurahav, R. B., Jiddu Joseph, Agas Mathew and Ajithkumar, S. 2020. Chylothorax in a Dog - Diagnosis and Management. Int.J.Curr.Microbiol.App.Sci. 9(04): 84-87.

doi: https://doi.org/10.20546/ijcmas.2020.904.011 